\title{
Cost-Effectiveness of the FreeStyle Libre ${ }^{\circledR}$ System Versus Blood Glucose Self-Monitoring in Individuals with Type 2 Diabetes on Insulin Treatment in Sweden
}

\author{
Johan Jendle • Katarina Eeg-Olofsson • Ann-Marie Svensson • \\ Stefan Franzen · Mark Lamotte $\cdot$ Fleur Levrat-Guillen
}

Received: September 1, 2021 / Accepted: October 7, 2021 / Published online: October 25, 2021

(C) The Author(s) 2021

\begin{abstract}
Introduction: Frequent glucose monitoring is essential to obtain glucose control. This is done by periodic self-monitoring of blood glucose (SMBG) using finger-prick testing, or by using continuous glucose monitoring devices,
\end{abstract}

Ann-Marie Svensson is deceased.

Supplementary Information The online version contains supplementary material available at https:// doi.org/10.1007/s13300-021-01172-1.

J. Jendle

Department of Medical Sciences, Örebro University, Örebro, Sweden

K. Eeg-Olofsson · A.-M. Svensson

Department of Molecular and Clinical Medicine, Institute of Medicine, University of Gothenburg,

Gothenburg, Sweden

K. Eeg-Olofsson · A.-M. Svensson · S. Franzen Swedish National Diabetes Register, Västra Götalandsregionen, Gothenburg, Sweden

S. Franzen

Department of Public Health and Community

Medicine, Health Metrics, University of

Gothenburg, Gothenburg, Sweden

M. Lamotte $(\bowtie)$

IQVIA, Global HEOR, Da Vincilaan 7, 1930

Zaventem, Belgium

e-mail: mark.lamotte@iqvia.com

F. Levrat-Guillen

Abbott Diabetes Care, Maidenhead, UK wherein a sensor records interstitial glucose data automatically. This study assessed the costeffectiveness of using the FreeStyle Libre Flash Continuous Glucose Monitoring System (FSL) compared to SMBG in individuals with type 2 diabetes (T2D) treated with insulin from a Swedish societal perspective.

Methods: Cost-effectiveness analysis was conducted using the IQVIA Core Diabetes model v9.5, with demographic and clinical inputs from a real-world study using Swedish National Diabetes Register data. Two cohorts of individuals with T2D were considered based on baseline HbA1C (HbA1c: 8-9\% [64-75 mmol/mol]; HbA1c: $9-12 \%$ [75-108 mmol/mol]). HbA1c reductions with FSL were $-0.41 \%(-4 \mathrm{mmol} /$ $\mathrm{mol}$; SD: $0.94 \%-10 \mathrm{mmol} / \mathrm{mol}$ ) and $-1.30 \%$ (- $14 \mathrm{mmol} / \mathrm{mol}$; SD: $1.40 \%-15 \mathrm{mmol} / \mathrm{mol}$ ) for the two cohorts, respectively. Utilities, treatment costs and diabetes-related complication costs were obtained from published sources. Analyses were conducted over a lifetime horizon, applying annual discounting of $3 \%$ on costs and effects. Scenario analyses and probabilistic sensitivity analyses were performed.

Results: Individuals with T2D who had a baseline $\mathrm{HbA} 1 \mathrm{c}$ of $8-9 \%(64-75 \mathrm{mmol} / \mathrm{mol})$ and 9-12\% (75-108 $\mathrm{mmol} / \mathrm{mol})$ and used FSL gained 0.50 and 0.57 quality-adjusted life-years (QALYs), respectively, at an incremental cost of SEK109,957 and SEK82,170 compared to SMBG, generating an incremental cost-utility ratio of SEK219,127 and SEK144,412 per QALY gained. 
Assuming a willingness-to-pay threshold of SEK300,000 per QALY gained, FSL use was considered cost-effective compared to SMBG for the majority of the individuals in both the lower and higher HbA1c cohorts. The key driver identified was the additional quality-of-life benefit that applied to FSL use.

Conclusion: The FreeStyle Libre Flash Continuous Glucose Monitoring System is a cost-effective glucose monitoring alternative to SMBG for individuals with T2D in Sweden who are treated with insulin but are not reaching their glycaemic goals.

Keywords: Continuous glucose monitoring; Cost-effectiveness; FreeStyle Libre flash continuous glucose monitoring system; Type 2 diabetes; Core diabetes model

\section{Key Summary Points}

\section{Why carry out this study?}

The economic burden of long-term diabetic complications in type 2 diabetes (T2D) is substantial, and Sweden bears one of the highest diabetes-related expenditures.

Frequent assessment of glucose levels is critical since poor glycaemic control is one of the key drivers of the total cost related to $\mathrm{T} 2 \mathrm{D}$.

The FreeStyle Libre ${ }^{\circledR}$ Flash Continuous Glucose Monitoring System (FSL) is a userfriendly sensor-based monitoring system that generates detailed glucose data needed for holistic glycaemic control.

The long-term cost-effectiveness of FSL in comparison to SMBG was assessed in individuals with T2D in Sweden who were treated with insulin but did not reach their glycaemic goals.

\section{What was learned from the study?}

Assuming a willingness to pay threshold of SEK300,000 per QALY gained, FSL has a more than $50 \%$ probability of being a cost-effective disease management option compared to SMBG.
Results were consistent irrespective of whether the patients had a baseline $\mathrm{HbA} 1 \mathrm{c}$ of $8-9 \%(64-75 \mathrm{mmol} / \mathrm{mol})$ or 9-12\% (75-108 $\mathrm{mmol} / \mathrm{mol})$.

A key factor driving the cost-effectiveness in favour of FSL was the additional quality-of-life benefit that applied to FSL use compared to SMBG use.

\section{INTRODUCTION}

Type 2 diabetes (T2D) and its complications are a significant cause of mortality and disability. Globally, around $9.3 \%$ of adults aged 20-75 years are reported to have diabetes, of whom approximately $90 \%$ are diagnosed with T2D [1]. In Sweden, the prevalence of diabetes in adults has been reported to be $7.2 \%$ [1]. Poor glycaemic control can lead to an increased burden of long-term diabetes complications, which is considered to be the key driver of the total cost related to T2D [2-4]. In Sweden alone, diabetes complications amounted to $€ 1,317$ per individual with diabetes in 2016 [5].

To improve glycaemic control, frequent testing of glucose levels via glucometers, selfmonitoring of blood glucose (SMBG) and continuous glucose monitoring have been shown to be critical in detecting and reducing the risk of hypoglycaemia and hyperglycaemia requiring hospitalisation or diabetic ketoacidosis [6-9]. However, SMBG only provides sporadic data and can be inconvenient to patients $[10,11]$. SMBG provides glucose data for only a single time point, with no glucose information between measurements, making it difficult to interpret the data.

The FreeStyle Libre ${ }^{\circledR}$ Flash Continuous Glucose Monitoring System (FSL; Abbott Diabetes Care, Witney, UK) is a sensor-based monitoring system that provides a user-friendly approach to generate the detailed glucose data needed for holistic glycaemic control. It uses a sensor that is worn by the individual and continuously monitors interstitial glucose levels. A reader or smartphone app scans the sensor to obtain the current glucose value, trends and variability and 
to access data from the previous 8 -h period. A meta-analysis assessing clinical trials and realworld studies has shown improvement in glycaemic levels with the use of flash glucose monitoring in individuals with type 1 diabetes (T1D) or T2D [12].

The FSL has been evaluated in comparison to SMBG in two pivotal trials, the IMPACT trial [13] in T1D and the REPLACE trial [14] in T2D. In the REPLACE trial, although there was no difference $(p=0.8222)$ in the primary outcome of change in HbA1c at 6 months between FSL and SMBG for the full analysis set, a significant reduction of $27.7 \%$ in hypoglycaemic episodes was observed in the FSL group compared to the SMBG group $(p=0.0164)$. Additionally, individuals aged under 65 years showed a significantly greater reduction in $\mathrm{HbA1c}$ in the FSL group compared to the SMBG group $(p=0.0301)$.

Several studies have demonstrated that people with diabetes have a better experience using FSL than they do with SMBG, since a scan using FSL is not only less stressful, painless and easier to understand [15], but it is also less time-consuming than traditional SMBG [16]. Further, a time trade-off analysis reported a significantly higher utility value for diabetes glucose monitoring using FSL compared with SMBG, suggesting that the use of FSL is associated with an improvement in health-related quality of life [17].

In addition, several real-world studies have demonstrated the effectiveness of flash glucose monitoring in individuals with T2D. A recently published prospective observational study found that it led to significant reductions in HbA1c, rate of hospitalisation and work absenteeism, and that it improved quality-of-life measures [18]. Findings from large retrospective studies have also reported similar clinical outcomes [19]. Recent analyses showed significant reductions in diabetes-related events and allcause hospitalisations among adults with T2D using flash glucose monitoring [9, 19]. An assessment of hospitalisation for acute diabetesrelated complications using the French national claims database showed a decrease in hospitalisation for hypoglycaemia $(-10.8 \%)$ as well as for hyperglycaemia $(-26.5 \%)$ among individuals with T2D. A recent real-world study using the Swedish National Diabetes Register (SweNDR) also demonstrated a significant reduction in $\mathrm{HbA1c}$ in individuals with T1D or T2D ( -0.44 for T1D and -0.66 for T2D) who were using FSL $[20,21]$.

The economic burden of long-term diabetic complications in T2D is substantial. Sweden bears one of the highest diabetes-related expenditures, and was ranked fifth globally in mean health expenditure per adult (20-75 years) with diabetes in 2019 (\$6643) [1]. A recent (2020) study by Andersson et al. also demonstrated that $75 \%$ of the total costs of hospital-based care are attributable to T2D [5]. Further, the costs of absences from work were found to be greater than those of hospital-based care, implying the need to consider treatment consequences from a societal perspective in Sweden [5]. Being an advanced technology, FSL is on the market at a higher cost than SMBG. Given the potential benefits associated with the device, the current study aimed to assess the long-term cost-effectiveness of FSL in comparison to SMBG in individuals with T2D who were treated with insulin but did not achieve their glycaemic goals.

\section{METHODS}

\section{Modelling Approach}

This study was performed using version 9.5 of the IQVIA Core Diabetes Model (IQVIA CDM). The IQVIA CDM is a non-product-specific diabetes policy analysis tool that was developed to determine the long-term health outcomes and economic consequences associated with interventions for T1D and T2D. The model includes a series of interdependent Markov sub-models that perform real-time simulations of the progression of diabetes-related complications and associated mortality. The model captures the cumulative incidence of complications, rates of clinical events, per-patient costs, life-years gained and quality-adjusted life-years (QALYs) gained over a lifelong time horizon. The model has been described previously and extensively 
validated against clinical and epidemiological studies [22, 23].

The present analyses took a Swedish societal perspective, evaluating both direct and indirect costs and effects over a lifetime horizon (up to 40 years). Costs and effects were discounted at $3 \%$ according to Swedish guidance [24]. All analyses were run with 1000 individuals for 1000 iterations.

This cost-effectiveness analysis is based on a previously conducted real-world study for which the authors obtained ethical committee approval. This study was submitted to the Swedish Ethical Review Authority, Etikprovningsmyndigheten (ref. no. Dnr 2020-06565).

\section{Model Inputs}

\section{Population}

The target population comprised individuals with T2D receiving insulin as background therapy for a minimum of 6 months and naïve to FSL at study initiation $[20,21]$. The present analysis included two different cohorts of individuals with T2D: one with HbA1c values of $8-9 \% \quad(64-75 \mathrm{mmol} / \mathrm{mol}$; average $8.5 \%$ or $69.4 \mathrm{mmol} / \mathrm{mol}$ ) and the other with $\mathrm{HbA} 1 \mathrm{c}$ values of $9-12 \%(75-108 \mathrm{mmol} / \mathrm{mol})$. Baseline characteristics for the two cohorts used in the model were derived from a real-world study using SweNDR [20, 21], which included nationwide data on individuals with T2D who were treated with insulin (mainly by multiple daily injections, and a few by continuous subcutaneous insulin infusion) for a minimum of 6 months. Missing baseline characteristics were obtained from the REPLACE trial [14], and were already used in a previous cost-effectiveness analysis of FSL in Sweden [25]. Starting age was 57 years, average duration of diabetes was 13 years, and $67 \%$ of the population were males. A summary of the baseline characteristics of individuals in the model is provided in Supplementary Table S1.

\section{Clinical Inputs}

Intervention Effect The data on the effect on HbA1c of using the FreeStyle Libre system was sourced from the SweNDR real-world study, which reported a reduction in $\mathrm{HbA} 1 \mathrm{c}$ level of $-0.41 \%$ $(-4 \mathrm{mmol} / \mathrm{mol})$ and $-1.30 \% \quad(-14 \mathrm{mmol} / \mathrm{mol})$ in individuals with $\mathrm{HbA1c}$ values of $8-9 \%$ (64-75 mmol/mol) and 9-12\% (75-108 mmol/ mol), respectively [20] (Table 1$)$. Since it was a single-arm study, the immediate impact of SMBG on HbA1c was assumed to be zero, as it was considered a continuation of the previous therapy. It was assumed that there were no other changes in the other risk factors (lipids, blood pressure, body mass index, smoking habits), as they were not reported in the study. The progression over time of $\mathrm{HbA1c}$ in the base case was predicted using the United Kingdom Prospective Diabetes Study (UKPDS) 68 progression equation [26]. A scenario analysis was also run using the SweNDR progression equation. The progressions over time of blood pressure and lipid levels beyond year 1 were estimated using the UKPDS and Framingham derived equations available as defaults in the IQVIA CDM.

Adverse Events The main adverse event captured in the model is hypoglycaemia. Hypoglycaemic events were defined as either nonsevere (they do not require third-party assistance) or severe (they require third-party medical or non-medical assistance). The rate for severe hypoglycaemic events was sourced from a published meta-analysis [27] and assumed to be the same for both the FSL and the SMBG arms. The estimates for the non-severe hypoglycaemia rate reported in the same meta-analysis were used for SMBG. To estimate the nonsevere hypoglycaemic event (NSHE) rate for FSL, the SMBG event rate was reduced by $27.7 \%$, based on the relative effect of FSL, as observed in the REPLACE trial [14]. A summary of intervention effects and adverse event data for the included intervention strategies is provided in Table 1.

\section{Costs}

As the societal perspective was taken, both direct costs and costs due to productivity loss were taken into account. Treatment-related costs differed between the two arms because the dose of insulin used and the number of SMBG tests varied. The lowest costs of pharmaceuticals, glucose monitor test strips and lancets 
Table 1 Treatment effects

$\begin{array}{llll}\text { Required values } & \text { Units/ } & \text { Reference/notes } \\ \text { FSL } & \text { SMBG } & \text { range } & \\ \text { (SD) } & & \end{array}$

\begin{tabular}{|c|c|c|c|c|}
\hline \multicolumn{5}{|l|}{ Physiological parameters } \\
\hline $\begin{array}{l}\text { Change in baseline HbAlc in individuals } \\
\text { with HbAlc } 8-9 \%(64-75 \mathrm{mmol} / \mathrm{mol})\end{array}$ & $\begin{array}{r}-0.41 \\
(0.94)\end{array}$ & 0.00 & $\%$-points & Eeg-Olofsson et al. 2020 [20] \\
\hline \multirow{3}{*}{$\begin{array}{l}\text { Change in baseline HbAlc in individuals } \\
\text { with HbAlc } 9-12 \%(75-108 \mathrm{mmol} / \mathrm{mol})\end{array}$} & $-4(10)$ & & $\mathrm{mmol} / \mathrm{mol}$ & \multirow{3}{*}{ Eeg-Olofsson et al. 2020 [20] } \\
\hline & $\begin{array}{r}-1.30 \\
(1.40)\end{array}$ & 0.00 & $\%$-points & \\
\hline & $\begin{array}{r}-14 \\
(15)\end{array}$ & & $\mathrm{mmol} / \mathrm{mol}$ & \\
\hline \multicolumn{5}{|l|}{ Adverse events } \\
\hline Non-severe hypoglycaemic event rate & 1685.00 & 2331.00 & $\begin{array}{l}/ 100 \text { pt. } \\
\text { yrs }\end{array}$ & $\begin{array}{l}\text { Calculated based on the REPLACE trial } \\
\text { [14] and Edridge et al. } 2015 \text { [27] }\end{array}$ \\
\hline $\begin{array}{l}\text { Severe hypoglycaemia } 1 \text { event rate (req. non. } \\
\text { med. assist.) }\end{array}$ & 0.00 & 0.00 & $\begin{array}{l}/ 100 \text { pt. } \\
\text { yrs }\end{array}$ & \\
\hline $\begin{array}{l}\text { Severe hypoglycaemia } 2 \text { event rate (req. med. } \\
\text { assist.) }\end{array}$ & 105.00 & 105.00 & $\begin{array}{l}/ 100 \text { pt. } \\
\text { yrs }\end{array}$ & $\begin{array}{l}\text { Calculated based on the REPLACE trial } \\
\text { [14] and Edridge et al. } 2015 \text { [27] }\end{array}$ \\
\hline
\end{tabular}

HbAlc haemoglobin A1C, FSL FreeStyle Libre Flash Continuous Glucose Monitoring System, Pt yrs patient-years, SMBG self-monitoring of blood glucose, $S D$ standard deviation

available from the Swedish Dental and Pharmaceutical Benefits Agency (TLV) were considered [28]. Table 2 summarises the unit costs and total annual costs of various interventions used in the model.

The cost of diabetes-related complications was sourced from the previously mentioned health economic analysis of FSL using the CDM [25] (Supplementary Table S2). The average salary for males and females and workdays lost due to complications and adverse events were also considered (Supplementary Table S3).

All costs were inflated to March 2020 using the consumer price index for Sweden from the Organisation for Economic Co-operation and Development [29].

\section{Utility}

The non-severe hypoglycaemia event disutility values for the FSL and SMBG arms were calculated using a previously published diminishing disutilities approach [30]. The literature shows that for the first few minor hypoglycaemic events, individuals experience relatively high disutilities; the disutility per event diminishes as the individual starts having more events. In addition, an intervention-related health utility benefit of 0.03 was applied to the FSL arm [17] (Supplementary Table S4).

\section{Analytical Approach}

\section{Base Case Analysis}

The base case analysis compared the cost-effectiveness of FSL with that of SMBG in two different cohorts of individuals with T2D who were on insulin, one with starting $\mathrm{HbA1c}$ values of $8-9 \%(64-75 \mathrm{mmol} / \mathrm{mol}$; average $8.5 \%$ or $69.4 \mathrm{mmol} / \mathrm{mol}$ ) and the other with starting HbA1c values of $9-12 \%(75-108 \mathrm{mmol} / \mathrm{mol})$ for a lifetime horizon (40 years). To predict 
Table 2 Intervention costs

\begin{tabular}{|c|c|c|}
\hline Cost parameter & $\begin{array}{l}\text { Required } \\
\text { values (SEK) }\end{array}$ & Source \\
\hline \multicolumn{3}{|l|}{ Intervention unit costs } \\
\hline $\begin{array}{l}\text { Insulin (Abasaglar Kwikpen, } \\
\text { 10-pack) (per unit injection pen) }\end{array}$ & 0.30 & Tariff 2019-11-28 \\
\hline Metformin (per 500-mg tablet) & 0.23 & \\
\hline FSL sensor & 420 & \\
\hline Reader (reimbursed every 2 years) & 599 & \\
\hline FSL (per test strip) & 2.40 & \\
\hline SMBG (per test strip) & 2.40 & \\
\hline Lancet & 0.23 & \\
\hline Extra physician visits & 1427 & Sodra Regionvardsnamnden 2014 [37] \\
\hline \multicolumn{3}{|l|}{ Total annual costs } \\
\hline FSL intervention costs for first year & 22,500 & $\begin{array}{l}\text { Sensors }(26 \times \text { SEK } 420.00)+\text { readers }(\text { SEK599.00/2 })+\text { insulin } \\
(85.2 \text { units } / \text { day } \times \text { SEK0.3 } / \text { per unit } \times 365.25)+1500 \mathrm{mg} \\
\text { metformin }(\text { SEK0.23 per } 500 \mathrm{mg} \text { tablet } \times 3 \times 365.25)+0.3 \\
\text { strips per day }(\text { SEK } 2.4 \times 0.3 \times 365.25)+\text { lancets } \\
(\text { SEK0.23 } \times 0.3 \times 365.25)+\text { extra physician visit } \\
(\text { SEK1426.59) }\end{array}$ \\
\hline $\begin{array}{l}\text { FSL intervention costs from second } \\
\text { year onwards }\end{array}$ & 21,074 & $\begin{array}{l}\text { Sensors }(26 \times \text { SEK } 420.00)+\text { readers }(\text { SEK599.00/2 })+\text { insulin } \\
(85.2 \text { units } / \text { day } \times \text { SEK0.3 } / \text { per unit } \times 365.25)+1500 \mathrm{mg} \\
\text { metformin }(\text { SEK0.23 per } 500 \mathrm{mg} \text { tablet } \times 3 \times 365.25)+0.3 \\
\text { strips per day }(\text { SEK } 2.4 \times 0.3 \times 365.25)+\text { lancets } \\
(\text { SEK } 2.4 \times 0.3 \times 365.25)\end{array}$ \\
\hline SMBG comparator costs & 12,503 & $\begin{array}{l}\text { Insulin }(87.8 \text { units/day } \times \text { SEK0.3/per unit } \times 365.25)+3 \text { strips } \\
\text { per day }(\text { SEK } 2.4 \times 3 \times 365.25)+\text { lancets } \\
(\text { SEK } 2.4 \times 3 \times 365.25)+1500 \mathrm{mg} \text { metformin }(\text { SEK } 0.23 \text { per } \\
500 \mathrm{mg} \text { tablet } \times 3 \times 365.25)\end{array}$ \\
\hline
\end{tabular}

FSL FreeStyle Libre Flash Continuous Glucose Monitoring System, OAD oral antidiabetic drug, SEK Swedish Krona, $S M B G$ self-monitoring of blood glucose

cardiovascular (CV) outcomes, the SweNDR T2D CV risk equation programmed into the IQVIA CDM was used in the base case analysis. Moreover, Sweden-specific life tables were used to predict non-specific mortality. These mortality rates represented the risk of death not covered in the complication and adverse event sub-models of the CDM.
For all simulations, the minimum approach method was applied to calculate the QALYs, wherein the utility value assigned was the lowest of the different comorbid conditions for individuals with multiple comorbidities. Thus, it was assumed that the disutility for comorbidities is not additive. 


\section{Uncertainty}

Scenario Analyses As extrapolation of longterm clinical outcomes is associated with uncertainty, scenario analyses were conducted to evaluate how changes to key parameters in the modelling analyses impact the results of the base case analyses. Details of the scenarios are presented in Supplementary Table S5.

One of the scenarios explored the impact of using the SweNDR progression equation instead of UKPDS equation for HbA1c progression. In another scenario, inputs were varied based on the published study by Yaron et al. (2019) [31]. In this scenario, the baseline HbA1c and a lower annual insulin dose as reported by Yaron et al. (2019) [31] were applied. The change in HbA1c was $-0.85 \%(0.45)$ for FSL and $-0.32 \%(0.39)$ for SMBG, and NSHE rates with FSL (170/100 patient-years) and SMBG (197/100 patientyears) were used. Other scenario analyses included the impact of a decrease in the price of the FSL sensor from SEK420 (base case) to SEK405 with no FSL reader cost, altering discount rates to $0 \%$ and $5 \%$, shortening the time horizon of the analyses to 5 years and 10 years, reducing treatment-related utility benefit to 0 , reducing treatment-related change in HbA1c to $0 \%$, changing the $\mathrm{CV}$ risk equation to UKPDS 82 [32] and including additional resource utilisation costs associated with SMBG only for the first year and for all years.

Probabilistic Sensitivity Analysis Probabilistic sensitivity analyses (PSA) were performed using Monte Carlo simulations together with a nonparametric bootstrapping approach to determine parameter uncertainty around cost-effectiveness outcomes. The parameters included in the PSA are the per individual characteristics, treatment efficacy, utility, and cost of complications. Log normal distributions and 10\% variation were applied to sample the costs of complications. Treatment effects were sampled based on the estimated standard error (SE) detailed in Table 1 . The utility data were varied according to the variability reported as standard deviation values in Supplementary Table S4. All were sampled following the beta distribution. To sample individuals' baseline characteristics, truncated normal distributions with the mean and SE reported in Supplementary Table S1 were used. Results are presented in the cost-effectiveness plane and as cost-effectiveness acceptability curves (CEAC).

\section{RESULTS}

\section{Base Case Analysis}

FreeStyle Libre Flash Continuous Glucose Monitoring System use provided additional life-years (LYs) (0.03) and higher QALYs (0.50) and total costs $($ SEK109,957) in individuals with T2D who had $\mathrm{HbA} 1 \mathrm{c}$ values of $8-9 \%(64-75 \mathrm{mmol} / \mathrm{mol})$, generating an estimated incremental cost-utility ratio (ICUR) of SEK219,127 per QALY gained. In individuals with HbA1c values of $9-12 \%$ (75-108 $\mathrm{mmol} / \mathrm{mol})$, the use of FSL resulted in higher LY (0.13), QALYs (0.57), and total costs (SEK82,170), generating an estimated ICUR of SEK144,412 per QALY gained. Assuming a willingness-to-pay (WTP)/accept threshold of SEK300,000 per QALY gained, the use of FSL can be considered cost-effective over a lifetime compared with SMBG. The results of the base case analysis are presented in Table 3.

For both cohorts, the base case analysis showed that higher direct and combined costs accrued for individuals using FSL over a lifetime compared with SMBG, which was mainly attributed to the higher treatment cost of FSL (Supplementary Fig. S1).

In terms of clinical outcomes, use of FSL was associated with lower risks of renal disease, $\mathrm{CV}$ disease, eye disease, ulcer, amputation, neuropathy, and hypoglycaemia over a lifetime as compared to SMBG (Supplementary Table S6). The analysis also showed comparable survival over time for users of FSL and users of SMBG.

\section{Scenario Analyses}

Reducing the cost of FSL resulted in a lower ICUR value than in the base case (HbA1c 8-9\% [64-75 mmol/mol]: SEK200,140; HbA1c 9-12\% [75-108 $\mathrm{mmol} / \mathrm{mol}]:$ SEK127,935). Altering the discount rate to $0 \%$ yielded higher ICUR values (HbA1c 8-9\% [64-75 mmol/mol]: SEK222,616 
Table 3 Cost-effectiveness results of the base case analysis

\begin{tabular}{|c|c|c|c|c|}
\hline & \multicolumn{2}{|c|}{ HbA1c 8-9\% (64-75 $\mathrm{mmol} / \mathrm{mol})$} & \multicolumn{2}{|c|}{ HbA1c 9-12\% (75-108 $\mathrm{mmol} / \mathrm{mol})$} \\
\hline & FSL arm & SMBG arm & FSL arm & SMBG arm \\
\hline LY (years) & 13.24 & 13.20 & 13.01 & 12.88 \\
\hline QALY (years) & 8.18 & 7.68 & 8.02 & 7.46 \\
\hline Total cost (SEK) & $1,849,767$ & $1,739,809$ & $1,878,221$ & $1,796,050$ \\
\hline \multicolumn{5}{|c|}{ Comparison intervention vs. comparator } \\
\hline Incremental LY & 0.03 & & 0.13 & \\
\hline Incremental QALY & 0.50 & & 0.57 & \\
\hline Incremental costs (SEK) & 109,958 & & 82,171 & \\
\hline ICER (SEK/LY gained) & $3,342,179$ & & 645,489 & \\
\hline ICUR (SEK/QALY gained) & 219,127 & & 144,412 & \\
\hline
\end{tabular}

FSL FreeStyle Libre Flash Continuous Glucose Monitoring System, HbAlc haemoglobin A1C, ICER incremental costeffectiveness ratio, ICUR incremental cost-utility ratio, $L Y$ life-year, $Q A L Y$ quality-adjusted life-year, SEK Swedish Krona, $S M B G$ self-monitoring of blood glucose

and HbA1c $\quad 9-12 \% \quad$ [75-108 $\mathrm{mmol} / \mathrm{mol}]$ : SEK151,823 per QALY gained) whereas altering the discount rate to $5 \%$ yielded lower ICUR values (HbA1c $\quad 8-9 \%$ [64-75 $\mathrm{mmol} / \mathrm{mol}]$ : SEK217,142; HbA1c 9-12\% [75-108 mmol/ mol]: SEK139,805) in comparison to the base case in both cohorts. In the scenario where the impact of using the SweNDR progression equation instead of the UKPDS equation for HbA1c progression was explored, the LY and QALY increased marginally with a slightly lower cost, resulting in an increase in the ICUR value as compared to the base case (HbA1c 8-9\% [64-75 mmol/mol]: SEK241,834; HbA1c 9-12\% [75-108 mmol/mol]: SEK198,757). Reducing the time horizon to 5 years and 10 years, respectively, led to lower ICUR values as compared to the base case in both cohorts ( 5 years: HbA1c 8-9\% [64-75 mmol/mol]: SEK205,579, HbA1c 9-12\% [75-108 mmol/mol]: SEK98,481; 10 years: HbA1c $8-9 \%$ [64-75 $\mathrm{mmol} / \mathrm{mol}]$ : SEK206,799, HbA1c 9-12\% [75-108 mmol/ mol]: SEK105,944).

The impact of removing the treatment utility benefit for FSL from the analysis was also tested. This generated a high ICUR in both cohorts (HbA1c 8-9\% [64-75 mmol/mol]: SEK1,259,
538; HbA1c 9-12\% [75-108 $\mathrm{mmol} / \mathrm{mol}]$ : SEK510,060); these ICURs were above the SEK300,000 threshold but within the identified potential threshold reported for Sweden (e.g. SEK208,000-827,000 per QALY in Persson (2010) [33]).

Removing the impact of FSL on HbA1c increased the ICUR to SEK252,576 and SEK252,639 for the two cohorts.

Applying a different $\mathrm{CV}$ risk equation (UKPDS 82) increased the ICUR to SEK220, 508 and SEK158,846 in the HbA1c 8-9\% (64-75 $\mathrm{mmol} / \mathrm{mol})$ and HbA1c $9-12 \%$ (75-108 $\mathrm{mmol} / \mathrm{mol})$ cohorts, respectively, in comparison to the base case. When the resource utilisation cost of SMBG for the first year of treatment was considered, it yielded lower ICUR values (HbA1c $\quad 8-9 \% \quad$ [64-75 $\mathrm{mmol} / \mathrm{mol}]$ : SEK194,571; HbA1c 9-12\% [75-108 mmol/ mol]: SEK121,735 per QALY gained) than in the base case. The results were consistent when the resource utilisation costs for the SMBG arm were extended beyond the first year.

Finally, the impact of varying the inputs based on the published study by Yaron et al. (2019) [31] (starting age 67 years, duration of diabetes 22 years, $\mathrm{HbA1c} 8.52 \%$ [70 $\mathrm{mmol} / \mathrm{mol}]$ ) 
Table 4 Cost-effectiveness results of scenario analyses

Scenarios HbAlc 8-9\% $(64-75 \mathrm{mmol} / \mathrm{mol})$

HbAlc 9-12\% (75-108 $\mathrm{mmol} / \mathrm{mol})$

Scenario A: Decreased FSL cost

Incremental cost (SEK)

100,430

72,795

ICUR (SEK/QALY gained)

200,140

127,935

Scenario B: Discount 0\%

Incremental cost (SEK)

156,165

120,244

ICUR (SEK/QALY gained)

222,616

151,823

Scenario B: Discount 5\%

Incremental cost (SEK)

90,006

65,764

ICUR (SEK/QALY gained)

217,142

139,805

Scenario C: Applying different HbAlc progression equation

Incremental cost (SEK)

124,133

106,792

ICUR (SEK/QALY gained)

241,834

198,757

Scenario D: Time horizon: 5 years

Incremental cost $(\mathrm{SEK})$

32,605

17,096

ICUR (SEK/QALY gained)

205,579

98,481

Scenario D: Time horizon: 10 years

Incremental cost (SEK)

59,145

34,803

ICUR (SEK/QALY gained)

206,799

105,944

Scenario E: Treatment-related utility benefit in FSL arm

Incremental cost (SEK)

109,958

82,171

ICUR (SEK/QALY gained)

$1,259,538$

510,060

Scenario F: Applying different CV risk equation
Incremental cost (SEK)
128,071
102,058
ICUR (SEK/QALY gained)
220,508
158,846

Scenario G: Considering resource utilisation cost in SMBG for first year
Incremental cost (SEK)
97,636
69,267
ICUR (SEK/QALY gained)
194,571
121,735

Scenario H: Considering impact of resource utilisation difference on all years

Incremental cost $(\mathrm{SEK})$

$-62,878$

$-87,339$

ICUR (SEK/QALY gained)

Dominant

Dominant

Scenario I: Considering inputs from Yaron et al. [31]
Incremental cost (SEK)
92,049
ICUR (SEK/QALY gained)
254,912 
Table 4 continued

\begin{tabular}{lcl}
\hline Scenarios & HbA1c 8-9\% $(\mathbf{6 4 - 7 5} \mathbf{~ m m o l} / \mathbf{m o l})$ & HbA1c 9-12\% $(\mathbf{7 5 - 1 0 8 ~} \mathbf{~ m o l} / \mathbf{m o l})$ \\
\hline Scenario J: Assuming no HbA1C reduction with FSL & \\
Incremental cost (SEK) & 119,544 & 116,870 \\
ICUR (SEK/QALY gained) & 252,576 & 252,639 \\
\hline
\end{tabular}

$C V$ cardiovascular, FSL FreeStyle Libre Flash Continuous Glucose Monitoring System, HbAlc haemoglobin A1C, SEK Swedish Krona, $S M B G$ self-monitoring of blood glucose

generated an estimated ICUR of SEK254,912 per QALY gained.

Overall, in all scenario analyses (except for that in which the utility benefits of FSL were lowered to 0.00), FSL remained cost-effective as compared to standard SMBG at a threshold of SEK300,000 per QALY gained in individuals with T2D on insulin treatment. The results of the scenario analyses are detailed in Table 4.

\section{Probabilistic Sensitivity Analysis}

In the cohort with $\mathrm{HbA1c}$ values of $8-9 \%$ $(64-75 \mathrm{mmol} / \mathrm{mol})$, the probability of FSL being cost-effective at the defined WTP threshold of SEK300,000 per QALY gained was 54\% (Fig. 1). In the cohort with HbA1c values of $9-12 \%$ $(75-108 \mathrm{mmol} / \mathrm{mol})$, the probability of the FreeStyle Libre system being cost-effective at the defined WTP threshold of SEK300,000 per QALY gained was 58\% (Fig. 1).

\section{DISCUSSION}

The current health economic analysis evaluated the long-term economic and clinical outcomes of the FreeStyle Libre Flash Continuous Glucose Monitoring System in comparison to SMBG in Swedish individuals with T2D who were treated with insulin but could not achieve their glycaemic goals. The analyses were conducted using real-world data.

The base case analysis showed that the FSL led to better health outcomes than SMBG over a lifetime, albeit at a higher cost. In the cohort with $\mathrm{HbA1c}$ values of 8-9\% (64-75 $\mathrm{mmol} / \mathrm{mol})$, use of FSL provided additional LYs (0.03) and QALYs (0.50) at an incremental cost of SEK109,957 compared to SMBG. Similarly, in the cohort with HbA1c values of $9-12 \%$ (75-108 $\mathrm{mmol} / \mathrm{mol})$, use of FSL resulted in gains in LY (0.13) and QALY (0.57) at an incremental cost of SEK82,170 compared to SMBG. Thus, the ICURs remained well within the identified potential threshold range for Sweden based on the literature (i.e. SEK330,000-827,000 per QALY in Persson (2010) [33]: SEK208, 000-625,000 per QALY based on the World Health Organization recommendation [34]) when combined costs were considered. Therefore, the use of FSL can be considered cost-effective over a lifetime as compared to standard SMBG glucose monitoring. The current analyses confirm the previously published work in which the cost-effectiveness was studied based on the REPLACE randomised clinical trial [25].

When the UKPDS $68 \mathrm{HbA1c}$ progression equation was used in the base case, there was a small decrease in HbA1c in the first year, even though no direct treatment effect was applied to SMBG; also, although the use of FSL was associated with a significant $\mathrm{HbA1c}$ reduction in the first year, both curves converged over time (Fig. 2). When the SweNDR HbA1c progression equation was used, HbA1c also decreased significantly in the SMBG arm. Nevertheless, the conclusions regarding cost-effectiveness remain similar. We also conducted an analysis removing the impact of FSL on HbA1c, and the costeffectiveness was maintained. 
$\mathbf{a}$

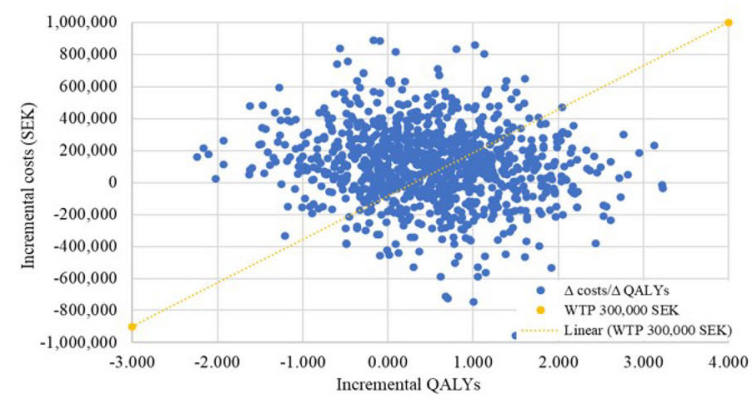

c

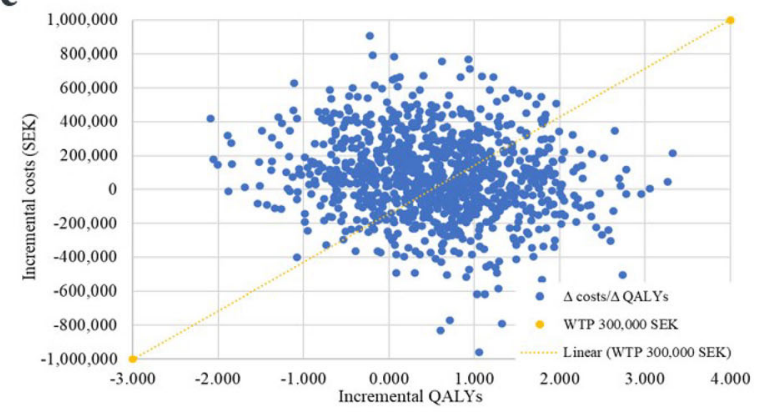

Fig. 1 Cost-effectiveness scatterplots and acceptability. a Cost-effectiveness plane for the base case analysis of the cohort with $\mathrm{HbAlc}$ values of $8-9 \%(64-75 \mathrm{mmol} / \mathrm{mol})$ (QALY). b Cost-effectiveness acceptability curve for the base case analysis of the cohort with HbAlc values of 8-9\% (64-75 mmol/mol) (QALY). c Cost-effectiveness

To examine the impacts of key assumptions on the base case results, additional scenario analyses were conducted. The results remained robust to explorations of almost all the examined alternate inputs. In all scenario analyses (except when the utility benefits of FSL were lowered to 0.00), the FSL remained cost-effective as compared to standard SMBG glucose monitoring at a threshold of SEK300,000 per QALY gained. However, when the utility benefits of FSL were removed, the treatment was no longer cost-effective. Nevertheless, not having to finger-prick can make the treatment more convenient and less stressful/painful for the individual. Previous studies using CDM have found that the cost-effectiveness of interventions for T2D is driven primarily by HbA1c, although the impact of hypoglycaemia can also b

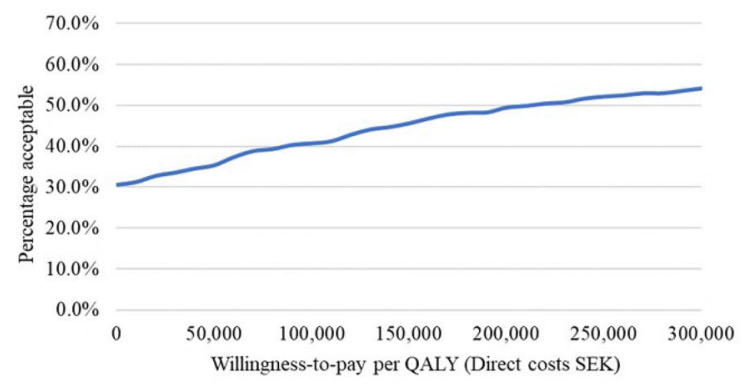

d

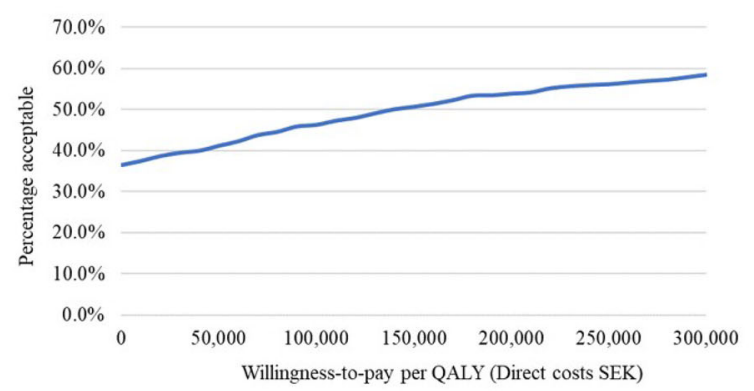

plane for the base case analysis of the cohort with $\mathrm{HbAlc}$ values of $9-12 \%(75-108 \mathrm{mmol} / \mathrm{mol})$ (QALY). d Costeffectiveness acceptability curve for the base case analysis of the cohort with HbAlc values of $9-12 \%$ (75-108 mmol/mol) (QALY). QALY quality-adjusted life year, SEK Swedish Krona, WTP willingness to pay

be significant $[35,36]$. Here, we have shown that applying a utility increment is also impactful.

The PSA findings showed that FSL was costeffective compared to SMBG in $54 \%$ of the simulations for the cohort of T2D individuals on insulin treatment with HbA1c values of $8-9 \%(64-75 \mathrm{mmol} / \mathrm{mol})$, and in $58 \%$ of the simulations for the cohort with HbA1c values of 9-12\% (75-108 $\mathrm{mmol} / \mathrm{mol})$.

There are certain limitations pertaining to the present analysis. Firstly, the analysis simplified the treatment pathway of individuals by assuming there is no step-up therapy in those individuals, and as such, glucose monitoring and insulin use do not change over time. Longterm real-world data are needed to clarify changes in glucose monitoring or medication 
a

HbAlc progression (UKPDS): $8 \%-9 \%$

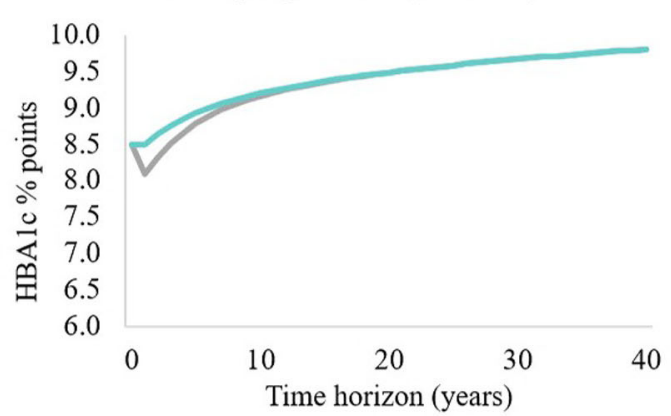

c $\quad \mathrm{HbA1c}$ progression (SweNDR): $8-9 \%$

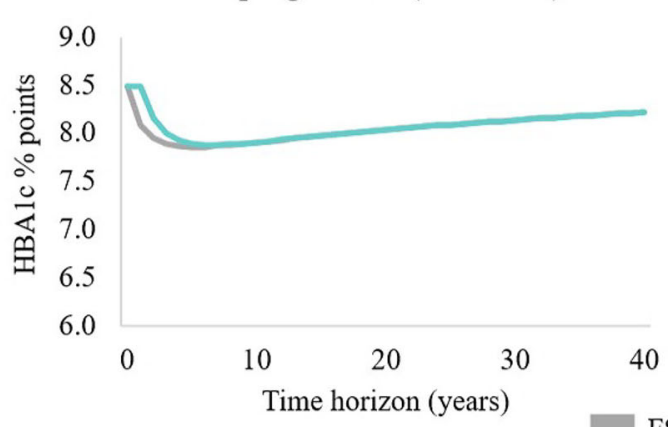

FSL arm

Fig. 2 Progression of $\mathrm{HbAlc}$ over time in the base case analysis. a Progression of HbAlc over time under UKPDS (base case) for the cohort with $\mathrm{HbAlc}$ values of $8-9 \%$ $(64-75 \mathrm{mmol} / \mathrm{mol})$. b Progression of HbAlc over time under UKPDS (base case) for the cohort with HbAlc values of $9-12 \%(75-108 \mathrm{mmol} / \mathrm{mol})$. c Progression of HbAlc over time under SweNDR (scenario analysis) for the cohort with HbAlc values of $8-9 \%$

based on the use of flash glucose monitoring and SMBG. For instance, the possible impacts of alternatives to the current algorithm on the precise lifetime costs and QALY of the model cohort are unknown. Secondly, this analysis assumed that NSHEs have no effect on the risk of subsequent severe hypoglycaemia as well as $\mathrm{CV}$ events and mortality, which may have led to a greater reduction in severe events with FSL than predicted. Another possible limitation was that the rate of use of strips and lancets with FSL was set at $0.3 / d$, which could be much more than what users are actually using. The same could be said about the three tests per day in the SMBG arm: it was less than that recommended
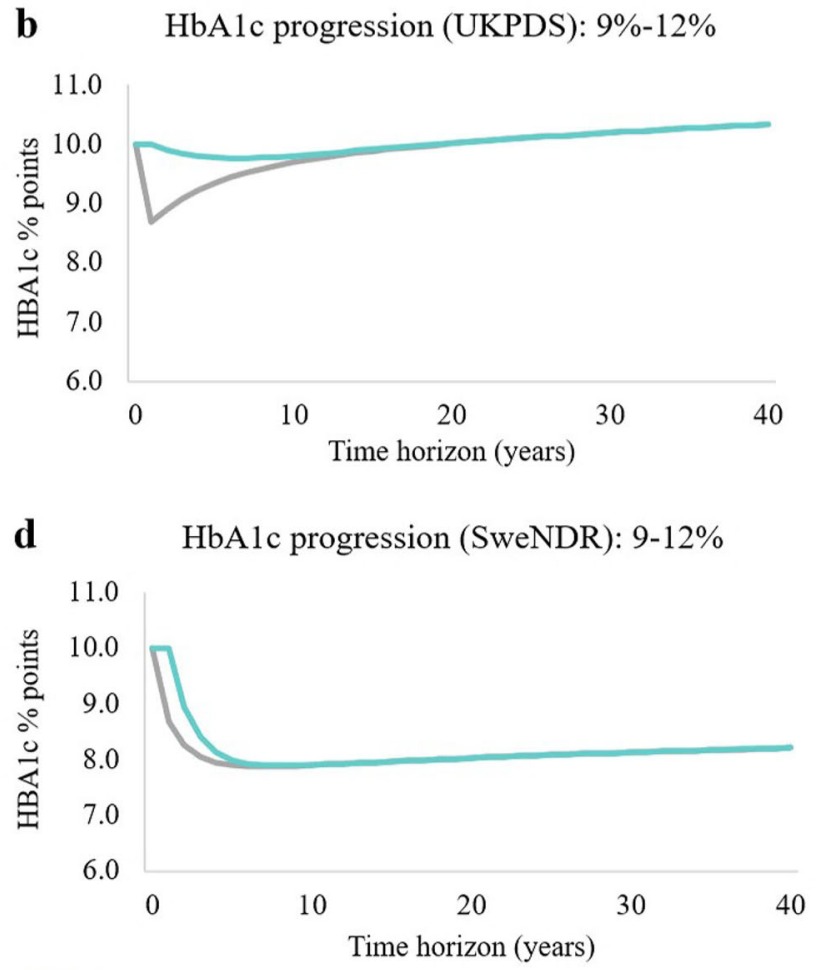

SMBG arm

(64-75 mmol/mol). d Progression of HbAlc over time under SweNDR (scenario analysis) for the cohort with HbAlc values of $9-12 \%(75-108 \mathrm{mmol} / \mathrm{mol})$. FSL FreeStyle Libre Flash Continuous Glucose Monitoring System, HbAlc haemoglobin A1C, $S M B G$ self-monitoring of blood glucose, SweNDR Swedish National Diabetes Register, UKPDS United Kingdom Prospective Diabetes Study

by treatment guidelines, but it may be more than the number performed in a real-life setting. Thus, if the utilisation of strips and lancets was increased to meet the guidelines, the costs in the SMBG arm would further increase, improving the results in favour of FSL. Also, hypoglycaemic events were not captured in the real-life study, and as such, event rates were assumed to be the same as in the previous costeffectiveness analyses. Lastly, it is also worth noting that the model inputs for a reduction in baseline HbA1c were based on a single-arm realworld study, and such observations are likely to overestimate the treatment effect in the absence of a control group. However, a scenario analysis 
showed that the impact of this assumption was small.

Nevertheless, one of the main strengths of this study is that the current analysis utilized baseline characteristics and effects on HbA1c that are representative of the individuals using FSL in the real-world setting in Sweden. Moreover, a Swedish CV risk equation was used in the cost-effectiveness analysis.

\section{CONCLUSION}

The FreeStyle Libre Flash Continuous Glucose Monitoring System is associated with improvements in clinical outcomes for Sweden-based patients with T2D on insulin who are not reaching their glycaemic goals. Taking the model assumptions into consideration, FSL has a more than $50 \%$ probability of being a costeffective disease management option compared to SMBG, based on a WTP threshold of SEK300,000 per QALY gained. Sensitivity and scenario analyses confirmed the robustness of the analysis.

\section{ACKNOWLEDGEMENTS}

Funding. This study, including the journal's Rapid Service and Open Access Fees, was funded by Abbott Diabetes Care.

Authorship. All named authors meet the International Committee of Medical Journal Editors criteria for authorship of this article, take responsibility for the integrity of the work, and have given their approval for this version to be published.

Author Contributions. Involvement per coauthor: J.J.: concept and design of real-world study, critical review of cost-effectiveness analyses results, writing of manuscript. K.E.O. concept and design of real-world study, critical review of cost-effectiveness analyses results and manuscript. A-M.S.: concept and design of realworld study, critical review of cost-effectiveness analyses results and manuscript. S.F.: concept, design and statistical analyses of real-world study, critical review of cost-effectiveness analyses results and manuscript. M.L.: concept, design and analyses of the cost-effectiveness study, critical review of cost-effectiveness results and manuscript. F.L.G.: concept, design and analyses of the cost-effectiveness study, critical review of cost-effectiveness results and manuscript.

Medical writing, editorial, and other assistance. We would like to thank Shreya Dam and Paranjoy Saharia for the medical writing support.

Disclosures. Mark Lamotte is a full-time employee of IQVIA. IQVIA received consulting fees to conduct the current research. Fleur Levrat-Guillen is employed by Abbott Diabetes Care. Johan Jendle has received lecturer, scientific advisory fees from; Abbott Diabetes Care, Ascentia, AstraZeneca, Boehringer Ingelheim, Eli Lilly, Medtronic, Merck Sharp \& Dohme, Nordic InfuCare, Novo Nordisk, and Sanofi. Katarina Eeg-Olofsson received honoraria for consulting and/or lecture fees from Abbott Diabetes Care, Eli Lilly, Novo Nordisk and Sanofi. Ann-Marie Svensson, Stefan Franzen have no relevant financial or conflicts of interest to declare. Ann-Marie Svensson passed away during the manuscript peer review process.

Compliance with Ethics Guidelines. This cost-effectiveness analysis is based on a previously conducted real world study for which the authors obtained ethical committee approval. This study was submitted to the Swedish Ethical Review Authority, Etikprovningsmyndigheten, (ref. no. Dnr 2020-06565).

Data Availability. All data generated or analysed during this study are included in this published article/as supplementary information files.

Open Access. This article is licensed under a Creative Commons Attribution-NonCommercial 4.0 International License, which permits any non-commercial use, sharing, adaptation, distribution and reproduction in any medium 
or format, as long as you give appropriate credit to the original author(s) and the source, provide a link to the Creative Commons licence, and indicate if changes were made. The images or other third party material in this article are included in the article's Creative Commons licence, unless indicated otherwise in a credit line to the material. If material is not included in the article's Creative Commons licence and your intended use is not permitted by statutory regulation or exceeds the permitted use, you will need to obtain permission directly from the copyright holder. To view a copy of this licence, visit http://creativecommons.org/licenses/by$\mathrm{nc} / 4.0 /$.

\section{REFERENCES}

1. IDF. IDF diabetes atlas, 9th edn [Internet]. 2019. https://www.diabetesatlas.org. Accessed $18 \mathrm{Mar}$ 2021.

2. ADA. Economic costs of diabetes in the U.S. in 2017. Diabetes Care. 2018;41(5):917-28. https:// doi.org/10.2337/dci18-0007.

3. Hex N, Bartlett C, Wright D, Taylor M, Varley D. Estimating the current and future costs of Type 1 and Type 2 diabetes in the UK, including direct health costs and indirect societal and productivity costs. Diabet Med. 2012;29(7):855-62. https://doi. org/10.1111/j.1464-5491.2012.03698.x.

4. Kähm K, Laxy M, Schneider U, Holle R. Exploring different strategies of assessing the economic impact of multiple diabetes-associated complications and their interactions: a large claims-based study in Germany. Pharmacoeconomics. 2019;37(1):63-74. https://doi.org/10.1007/s40273018-0699-1.

5. Andersson E, Persson S, Hallén N, et al. Costs of diabetes complications: hospital-based care and absence from work for 392,200 people with type 2 diabetes and matched control participants in Sweden. Diabetologia. 2020;63(12):2582-94. https:// doi.org/10.1007/s00125-020-05277-3.

6. NICE. Type 2 diabetes in adults: management [Internet]. 2015. https://www.nice.org.uk/guidance/ ng28/resources/type-2-diabetes-in-adultsmanagement-pdf-1837338615493. Accessed 18 Mar 2021.
7. American Diabetes Association. 6. Glycemic targets. Diabetes Care. 2017;40(Suppl 1):S48-S56. https:// doi.org/10.2337/dc17-S009.

8. Yeh HC, Brown TT, Maruthur N, et al. Comparative effectiveness and safety of methods of insulin delivery and glucose monitoring for diabetes mellitus: a systematic review and meta-analysis. Ann Intern Med. 2012;157(5):336-47. https://doi.org/ 10.7326/0003-4819-157-5-201209040-00508.

9. Roussel R, Riveline J-P, Vicaut E, et al. Important drop rate of acute diabetes complications in people with type 1 or type 2 diabetes after initiation of flash glucose monitoring in France: the RELIEF study. Diabetes Care. 2021:dc201690. https://doi. org/10.2337/dc20-1690.

10. Hellmund R. Self-assessment of glucose levels in the real world is less frequent than proposed in major guidelines. Diabetes. 2015;64(Suppl 1):A246-A.

11. Nardacci EA, Bode BW, Hirsch IB. Individualizing care for the many: the evolving role of professional continuous glucose monitoring systems in clinical practice. Diabetes Educ. 2010;36(Suppl 1):4S-19S (quiz 20S-1S). https://doi.org/10.1177/ 0145721710362798 .

12. Evans M, Welsh Z, Ells S, Seibold A. The impact of flash glucose monitoring on glycaemic control as measured by HbA1c: a meta-analysis of clinical trials and real-world observational studies. Diabetes Ther. 2020;11(1):83-95. https://doi.org/10.1007/ s13300-019-00720-0.

13. Bolinder J, Antuna R, Geelhoed-Duijvestijn P, Kröger J, Weitgasser R. Novel glucose-sensing technology and hypoglycaemia in type 1 diabetes: a multicentre, non-masked, randomised controlled trial. Lancet. 2016;388(10057):2254-63. https://doi. org/10.1016/s0140-6736(16)31535-5.

14. Haak T, Hanaire H, Ajjan R, Hermanns N, Riveline JP, Rayman G. Flash glucose-sensing technology as a replacement for blood glucose monitoring for the management of insulin-treated type 2 diabetes: a multicenter, open-label randomized controlled trial. Diabetes Ther. 2017;8(1):55-73. https://doi. org/10.1007/s13300-016-0223-6.

15. Abbott Diabetes Care. User experience study (data on file). 2014.

16. Rittmeyer D, Schmid C, Haug C, Freckmann G. A novel glucose monitoring system versus a conventional SMBG system: time and step analysis. Diabetes Technol Ther. 2015;17:A89-A89.

17. Matza LS, Stewart KD, Davies EW, Hellmund R, Polonsky WH, Kerr D. Health state utilities associated with glucose monitoring devices. Value 
Health. 2017;20(3):507-11. https://doi.org/10. 1016/j.jval.2016.10.007.

18. Fokkert M, van Dijk P, Edens $M$, et al. Improved well-being and decreased disease burden after 1 -year use of flash glucose monitoring (FLARENL4). BMJ Open Diabetes Res Care. 2019;7(1): e000809-e. $\quad$ https://doi.org/10.1136/bmjdrc-2019000809.

19. Bailey CJ, Gavin JR 3rd. Flash continuous glucose monitoring: a summary review of recent real-world evidence. Clin Diabetes. 2021;39(1):64-71. https:// doi.org/10.2337/cd20-0076.

20. Eeg-Olofsson K, Svensson A-M, Franzen S, Ismail HA, Tornblom M, Levrat-Guillen F. 74-LB: sustainable $\mathrm{HbA} 1 \mathrm{c}$ decrease at 12 months for adults with type 1 and type 2 diabetes using the FreeStyle Libre system: a study within the National Diabetes Register in Sweden. American Diabetes Association's 80th Scientific Session. Diabetes. 2020;69(Supplement 1). https://doi.org/10.2337/ db20-74-LB.

21. Nathanson D, Svensson AM, Miftaraj M, Franzén S, Bolinder J, Eeg-Olofsson K. Effect of flash glucose monitoring in adults with type 1 diabetes: a nationwide, longitudinal observational study of 14,372 flash users compared with 7691 glucose sensor naive controls. Diabetologia. 2021;64(7): 1595-603. https://doi.org/10.1007/s00125-02105437-z.

22. Palmer AJ, Roze S, Valentine WJ, et al. The Core Diabetes Model: Projecting long-term clinical outcomes, costs and cost-effectiveness of interventions in diabetes mellitus (types 1 and 2) to support clinical and reimbursement decision-making. Curr Med Res Opin. 2004;20(Suppl 1):S5-26. https://doi. org/10.1185/030079904x1980.

23. McEwan P, Foos V, Palmer JL, Lamotte M, Lloyd A, Grant D. Validation of the IMS CORE diabetes model. Value Health. 2014;17(6):714-24. https:// doi.org/10.1016/j.jval.2014.07.007.

24. Läkemedelsförmånsnämndens. Allmänna råd om ekonomiska utvärderingar (Medical Benefits Board General Advice for Economic Evaluations) [Internet]. 2003. https://www.tlv.se/download/18. 2e53241415e842ce95514e9/1510316396792/

Guidelines-for-economic-evaluations-LFNAR-20032.pdf.

25. Bilir SP, Hellmund R, Wehler E, Li H, Munakata J, Lamotte M. The cost-effectiveness of a flash glucose monitoring system for management of patients with type 2 diabetes receiving intensive insulin treatment in Sweden. Eur Endocrinol. 2018;14(2): 80-5. https://doi.org/10.17925/ee.2018.14.2.80.
26. Clarke PM, Gray AM, Briggs A, et al. A model to estimate the lifetime health outcomes of patients with type 2 diabetes: the United Kingdom Prospective Diabetes Study (UKPDS) Outcomes Model (UKPDS no. 68). Diabetologia. 2004;47(10): 1747-59. https://doi.org/10.1007/s00125-0041527-z.

27. Edridge CL, Dunkley AJ, Bodicoat DH, et al. Prevalence and incidence of hypoglycaemia in 532,542 people with type 2 diabetes on oral therapies and insulin: a systematic review and meta-analysis of population based studies. PLOS ONE. 2015;10(6): e0126427. https://doi.org/10.1371/journal.pone. 0126427.

28. TLV (Tandvårds-OCH Läkemedelsförmånsverket). Drug database [Internet]. 2013. http://www.tlv.se/ beslut/sok/lakemedel/. Accessed 18 Mar 2021.

29. OECD. Pensions at a glance 2013: OECD and G20 indicators [Internet]. 2013. https://doi.org/10.1787/ pension_glance-2013-en. Accessed 18 Mar 2021.

30. Lauridsen JT, Lønborg J, Gundgaard J, Jensen HH. Diminishing marginal disutility of hypoglycaemic events: results from a time trade-off survey in five countries. Qual Life Res. 2014;23(9):2645-50. https://doi.org/10.1007/s11136-014-0712-X.

31. Yaron M, Roitman E, Aharon-Hananel G, et al. Effect of flash glucose monitoring technology on glycemic control and treatment satisfaction in patients with type 2 diabetes. Diabetes Care. 2019;42(7):1178-84. https://doi.org/10.2337/dc180166.

32. Hayes AJ, Leal J, Gray AM, Holman RR, Clarke PM. UKPDS outcomes model 2: a new version of a model to simulate lifetime health outcomes of patients with type 2 diabetes mellitus using data from the 30 year United Kingdom Prospective Diabetes Study: UKPDS 82. Diabetologia. 2013;56(9):1925-33. https://doi.org/10.1007/ s00125-013-2940-y.

33. The Swedish Institute for Economics (IHE). Value \& valuation of health technologies: the Swedish experience [Internet]. 2010. https://www.swisshta. ch/index.php/Internationale_Erfahrungen. html?file=tl_files/SwissHTA/documents/Workshop_ 11_2010/Praesentationen/Praesentation_Persson_ 20101005.pdf.

34. WHO. Cost-effectiveness thresholds used in CHOICE analyses [Internet]. 2014. http://www. who.int/choice/costs/CER_thresholds/en/. Accessed Sep 2020.

35. Goodall G, Jendle JH, Valentine WJ, et al. Biphasic insulin aspart 70/30 vs. insulin glargine in insulin naïve type 2 diabetes patients: modelling the long- 
term health economic implications in a Swedish setting. Int J Clin Pract. 2008;62(6):869-76. https:// doi.org/10.1111/j.1742-1241.2008.01766.x.

36. McEwan P, Evans M, Lamotte M, Foos V. Assessing the relative contribution to changes in quality-adjusted life expectancy associated with Hba1c, weight and hypoglycaemia across multiple risk equations with the core diabetes model (CDM). Value Health. 2015;18(3):A23.

37. Sodra Regionvardsnamnden. 2014. 18 March 2021. https://sodrasjukvardsregionen.se/sodraregionvardsnamnden/. 